\title{
SELETIVIDADE DO ÓLEO DE PINHÃO MANSO (JATROPHA CURCAS L.) NA MICROFLOTAÇÃO DE APATITA, CALCITA E QUARTZO
}

\author{
André Carlos Silva ${ }^{\prime}$ \\ Izabela Letícia Almeida de Moraes ${ }^{2}$ \\ Elenice Maria Schons Silva \\ Carlos Murilo Silva Filho ${ }^{1}$ \\ Débora Nascimento Sousa ${ }^{3}$
}

\section{Resumo}

A flotação de minério fosfático sílico-carbonatado, tal como o presente no Complexo Ultramáfico Alcalino e Carbonatítico de Catalão I, tem baixa seletividade entre minerais da família da apatita e carbonatos. Testes de microflotação em tubo de Hallimond com óleo de pinhão manso saponificado foram realizados visando mensurar a recuperação de apatita, calcita e quartzo. Cinco concentrações do coletor foram testadas em duas condições de saponificação (temperatura ambiente e a $90^{\circ} \mathrm{C}$ ). Três diferentes valores de $\mathrm{pH}$ foram testados $(8,9$ e I0), totalizando 90 ensaios para cada mineral. As amostras minerais foram analisadas por MEV, EDS, fluorescência e difração de raios- $X$, bem como tiveram seu potencial zeta medido. O óleo de pinhão manso apresentou significativa recuperação de apatita e calcita e seletividade na flotação dos minerais testados.

Palavras-chave: Microflotação; Fosfato; Coletor; Seletividade.

\section{JATROPHA CURCAS L. SELECTIVITY IN APATITE, CALCITE AND QUARTZ MICROFLOTATION}

\begin{abstract}
The flotation of Phosphate ore with silicate-carbonate gangue, such as those present in Catalão I Alkaline Ultramafic and Carbonatitic Complex has low selectivity between apatite mineral family and carbonate. Hallimond tube microflotation tests with saponified Jatropha Curcas $L$ oil were carried out to measure the recovery of apatite, calcite and quartz. Five concentrations of the collector under two saponification conditions (room temperature and $90{ }^{\circ} \mathrm{C}$ ) were tested. Three different $\mathrm{pH}$ values were analysed $(8,9$ and 10$)$, totalling 90 assays for each mineral. The mineral samples were analysed by SEM, EDS, fluorescence and X-rays diffraction, and had their zeta potential measured. The Jatropha Curcas oil presented significant recovery of apatite and calcite and selectivity in the flotation of the tested minerals.
\end{abstract}

Keywords: Microflotation; Phosphate; Collector; Selectivity.

\section{INTRODUÇÃO}

No Brasil as jazidas de rocha fosfática são tipicamente de origem ígnea ou sedimentar. As rochas de origem ígnea brasileiras correspondem, em geral, a minérios mais complexos. A variedade mineralógica predominante da apatita é a fluorapatita, existindo também a presença de carbonatoapatita e hidroxiapatita associadas a fosfatos secundários, óxidos de ferro (magnetita, goethita e limonita), micas e minerais portadores de nióbio, titânio e bário. Segundo Ribeiro [I] as maiores reservas de rocha fosfática estão localizadas nos Complexos Carbonatíticos de Catalão-GO e do Barreiro-MG. De acordo com Santana [2] a rota de processamento adequada a concentração de minério fosfático

\footnotetext{
'Laboratório de Modelamento e Pesquisa em Processamento Mineral - LaMPPMin, Curso de Engenharia de Minas, Universidade Federal de Goiás UFG, Catalão, GO, Brasil. E-mail: ancarsil@ufg.br

2Programa de Mestrado Profissional em Gestão Organizacional, Universidade Federal de Goiás - UFG, Catalão, GO, Brasil.

${ }^{3}$ Programa de Doutorado em Ciências Exatas e Tecnológicas, Instituto Federal Goiano, Campus Avançado Catalão, Universidade Federal de Goiás UFG, Catalão, GO, Brasil.
} 
depende da sua origem e da natureza dos minerais de ganga (silicatos, carbonatos ou óxidos). Para Oliveira [3] os principais minerais associados à rocha fosfática são calcita, dolomita, sílica e óxidos de ferro, alumínio e magnésio.

A presença de carbonatos no concentrado de rocha fosfática tem um impacto considerável no custo de produção do ácido fosfórico, uma vez que o ácido sulfúrico será consumido pelos mesmos. O magnésio é a impureza mais indesejável neste concentrado por apresentar efeito negativo na taxa de filtração e na capacidade do filtro de concentrado. Além de aumentar a viscosidade do ácido superfosfórico, o magnésio diminui a quantidade de $\mathrm{P}_{2} \mathrm{O}_{5}$ solúvel durante a acidulação [4].

A produção de ácido fosfórico é prejudicada também pela presença de silicatos ocorrendo a reação de formação de ácido fluorídrico durante a acidulação do concentrado de rocha fosfática, o mesmo reage com a sílica formando tretafluoreto de silício gasoso, que é altamente inflamável. Tal gás deve ser direcionado para um sistema de lavagem de gases, onde é absorvido por água gerando ácido fluossilícico (também referido como ácido hexafluorossilícico, $\mathrm{H}_{2} \mathrm{SiF}_{6}$ ) líquido [5].

A separação dos minerais presentes na rocha fosfática é complexa devido, principalmente, à semelhança das propriedades físico-químicas de superfície dos mesmos. A flotação do minério sílico-carbonatado tem baixa seletividade em relação à calcita (ou dolomita) e a apatita [3]. A baixa seletividade de separação entre apatita e carbonatos por flotação tem sua explicação no fato de que os coletores utilizados (tipicamente ácidos graxos saponificados) são adsorvidos na superfície da apatita em função da presença do íon cálcio, que também está presente na calcita e na dolomita [6]. Ainda segundo o mesmo autor a flotação utilizando ácidos graxos como reagentes coletores é a principal técnica de concentração empregada no processamento de rochas fosfáticas, correspondendo à $60 \%$ do fosfato comercializado industrialmente. Apesar dos ácidos graxos serem seletivos ao quartzo, é desejável que o concentrado final apresente teores de $\mathrm{SiO}_{2}$ abaixo de 3\%. Segundo Loureiro et al. [7] - $\mathrm{SiO}_{2}$ forma complexos com o magnésio e esse fato pode estar associado à redução da seletividade apresentada na flotação quando em presença deste contaminante.

O pinhão manso (Jatropha Curcas L.) é uma espécie oleaginosa, arbustiva, pertencente à família Euphorbiaceae. Dentre as vantagens desta planta estão a alta produtividade de óleo, baixo custo de produção, resistência às diversas variações de solo e clima e resistência ao estresse hídrico. De acordo com Purcino e Drummond [8] o pinhão manso apresenta boa conservação da semente colhida, podendo ser armazenada por longos períodos sem a deterioração do óleo. Segundo Rosado et al. [9] o cultivo dessa espécie oleaginosa perene ocorre em várias regiões brasileiras, tendo sido trazida para o Brasil para ser utilizada como cerca viva e para produção de óleo em pequena escala.

Tendo em vista o potencial técnico e econômico do óleo pinhão manso como fonte de ácidos graxos para a flotação de minerais buscou-se verificar a seletividade do mesmo na flotação de apatita e a sua ganga (calcita e quartzo) visando uma possível aplicação industrial deste do óleo como coletor na flotação de minérios fosfáticos sílico-carbonatados.

\section{METODOLOGIA}

O óleo de pinhão manso foi caracterizado através de seus índices de saponificação $\left(I_{S}\right)$, de acidez $\left(I_{A}\right)$ e grau de saponificação $\left(G_{s}\right)$ utilizando a metodologia descrita por Oliveira [10]. O perfil lipídico do óleo foi determinado por cromatografia gasosa na Embrapa Agroenergia, utilizando um cromatógrafo AGILENT 7890A com injetor automático G6500-CTC e coluna DB-Way de $30 \mathrm{~m}$.

Dois métodos de saponificação para o óleo de pinhão manso foram testados. A saponificação a quente foi realizada a $90{ }^{\circ} \mathrm{C}$ seguindo a metodologia descrita por Costa [ $\mathrm{I}$ I] e a saponificação a frio (realizada em temperatura ambiente) seguindo a metodologia descrita por Silva [12].

O coletor industrial Flotigam 5806 da Clariant foi utilizado como padrão de comparação da recuperação em relação ao óleo do pinhão manso. Os dados utilizados de microflotação com Flotigam 5806 foram extraídos da literatura [13].

Os testes de microflotação foram realizados em tubo de Hallimond modificado. A Tabela I apresenta as condições operacionais adotadas. Os tempos de condicionamento e de flotação bem como a pressão de ar foram adotados de acordo com Costa [II]. Adotou-se a vazão de ar de $40 \mathrm{~cm}^{3} / \mathrm{min}$, já que esta proporciona o menor arraste hidráulico para partículas minerais na granulometria de $-150+106 \mu \mathrm{m}$ (ou $-100+150 \#$ ) [14]. Todos os testes foram realizados em triplicata.

Amostras de apatita, calcita e quartzo adquiridas da Mineração Zé da Estrada, situada em Araçuaí/MG, foram cominuídas em moinho de bolas, peneiradas a úmido utilizando um peneirador vibratório vertical e peneiras da série Tyler por 15 minutos. Após secagem em estufa à temperatura de $60{ }^{\circ} \mathrm{C}$ por 24 horas, as alíquotas retidas nas peneiras foram submetidas a separação magnética para a remoção de possíveis contaminações magnéticas utilizando um ímã de terras raras com campo de $2.000 \mathrm{G}$.

Tabela I. Variáveis operacionais adotadas nos testes de microflotação

\begin{tabular}{lc}
\hline \multicolumn{1}{c}{ Variável operacional } & Valor adotado \\
\hline Massa do mineral $(\mathrm{g})$ & $\mathrm{I}$ \\
Tempo de flotação $(\mathrm{min})$ & $\mathrm{I}$ \\
Tempo de condicionamento $(\mathrm{min})$ & 7 \\
Pressão de $\mathrm{ar}(\mathrm{psi})$ & 10 \\
Vazão de $\operatorname{ar}\left(\mathrm{cm}^{3} / \mathrm{min}\right)$ & 40 \\
$\mathrm{pH}$ & 8,9 e 10 \\
Granulometria $(\mu \mathrm{m})$ & $-150+106 \mu \mathrm{m}$ \\
Concentração do coletor $(\mathrm{mg} / \mathrm{L})$ & $\mathrm{I}, 0 ; 2,5 ; 5,0 ; 7,5$ e I0,0 \\
\hline
\end{tabular}


Após a preparação as amostras passantes na peneira de abertura $150 \mu \mathrm{m}$ e retidas na peneira de abertura $106 \mu \mathrm{m}$ foram caracterizadas por difração e espectrometria de fluorescência de raios-X, MEV e EDS.

As medidas de difração de raios- $X$ foram realizadas na UNIFESSPA em um difratômetro de raios- $X$ da PANalytical modelo Empyrean utilizando a geometria de reflexão Bragg-Brentano $(\theta: 2 \theta)$, que possui um monocromador de grafite pirolítico, operando a $30 \mathrm{kV} / 15 \mathrm{~mA}$, com passo angular de $0,02^{\circ}$ e tempo de aquisição de 2 segundos para a calcita e apatita e de I segundo para o quartzo. A fluorescência de raios-X foi realizada pela Copebrás S/A utilizando um $A X I O X$ MAX, série DY e ${ }^{\circ} 500$ I da PANalytical. Imagens de MEV foram obtidas no Laboratório Multiusuário de Microscopia de Alta Resolução (LabMic) da UFG utilizando um Jeol, JSM - 6610 e EDS da Thermo Scientific NSS Spectral Imaging. As medidas de potencial zeta das amostras minerais foram realizadas na faixa de $\mathrm{pH}$ 3,5 a 12,5 em água destilada, sendo o eletrólito indiferente utilizado o cloreto de potássio na concentração de $10^{-3} \mathrm{~mol} / \mathrm{L}$. O pH foi ajustado com hidróxido de sódio e ácido clorídrico a $1 \%$. As medidas foram realizadas em triplicatas no Laboratório de Propriedades Interfaciais da Escola de Minas da UFOP, utilizando um Zetasizer Nano modelo ZS90 da Malven e software Zetasizer. Todas as medidas foram feitas em triplicatas.

\section{RESULTADOS E DISCUSSÃO}

A Tabela 2 apresenta um sumário comparativo dos índices acidez $\left(I_{A}\right)$, de saponificação $\left(I_{S}\right)$ e do grau de saponificação $\left(G_{s}\right)$ para o pinhão manso comparado com outros óleos utilizados em testes de microflotação em tubo de Hallimond disponíveis na literatura. $\mathrm{O}$ valor médio do $\mathrm{I}_{\mathrm{A}}$ do óleo de pinhão manso foi de 7,67 \pm 0, $19 \mathrm{mg} \mathrm{KOH} / \mathrm{g}$ óleo, indicando que este apresenta ácidos graxos livres em sua composição. $\mathrm{O} \mathrm{I}_{\mathrm{s}}$ obtido para o pinhão manso foi de 182,57 \pm 10,14 mg KOH/g óleo. Segundo Costa [II], quanto maior for $\circ \mathrm{I}_{\mathrm{s}}$, menor quantidade desse reagente será necessária na flotação de apatita. Nota-se que $\circ \mathrm{I}_{\mathrm{S}}$ obtido foi um dos menores, sendo maior apenas que 0 óleo da polpa da macaúba. $\mathrm{O} \mathrm{G}_{\mathrm{s}}$ encontrado foi de $72,75 \%$, indicando que o óleo de pinhão manso apresenta $27,25 \%$ de matéria insaponificável. Segundo Silva [12] o $G_{s}$ do óleo de pequi é influenciado pelo tempo de maturação do óleo saponificado. Ou seja, quanto maior o tempo de maturação do óleo saponificado maior foi a recuperação de apatita nos ensaios de microflotação.

Na Figura I são apresentados os perfis lipídicos dos óleos da Tabela I. Os ácidos graxos predominantes no pinhão manso são o ácido linoleico (42,88\%) e oleico (33,96\%). Os ácidos insaturados correspondem a $84,24 \%$ da composição do óleo de pinhão manso, sendo estes os ácidos graxos mais importantes para a flotação. Tal resultado explicita o potencial do óleo de pinhão manso para ser utilizado como coletor. Os óleos de açaí e andiroba possuem predominância em ácidos insaturados, o que não ocorre com o óleo da castanha de macaúba (54,5 I\%). Costa [ I I] afirma que sais de ácidos graxos insaturados são mais solúveis em água do que os de ácidos saturados de mesmo número de átomos de carbono. Isto é devido ao fato da instauração da dupla ligação presente nos ácidos graxos insaturados apresentar um caráter ligeiramente polar (presença do par de elétrons da ligação), atraindo assim moléculas de água.

A Tabela 3 apresentada os resultados da fluorescência de raios- $X$ das amostras minerais. A coluna outros representa a soma dos óxidos $\mathrm{BaO}, \mathrm{CuO}, \mathrm{HfO}_{2}, \mathrm{Y}_{2} \mathrm{O}_{3}, \mathrm{Yb}_{2} \mathrm{O}_{3}, \mathrm{WO}_{3}$, $\mathrm{TiO}_{2}, \mathrm{ThO}_{2}, \mathrm{SrO}$ e SO , e dos elementos $\mathrm{Cl}$ e I. A apatita apresentou quantidades de $\mathrm{P}_{2} \mathrm{O}_{5}$ e $\mathrm{CaO}$ compatíveis com um grau de pureza de aproximadamente $93 \%$. Para a calcita, o teor de $\mathrm{CaO}(92,58 \%)$ indicou pureza do mineral de aproximadamente $92 \%$. A amostra de quartzo apresentou pureza de aproximadamente $95 \%$.

As Figuras $2 \mathrm{a}$ e $2 \mathrm{~b}$ apresentam imagens obtidas por MEV para as amostras de apatita por elétrons retro espalhados.

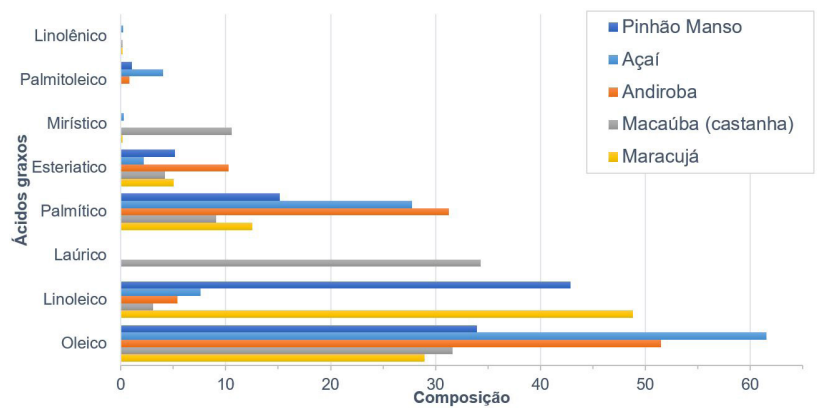

Figura I. Comparação da composição lipídica do óleo de pinhão manso e demais óleos vegetais utilizados na microflotação.

Tabela 2. Comparação do óleo de pinhão manso com outros óleos utilizados em testes de microflotação

\begin{tabular}{|c|c|c|c|c|}
\hline Óleo & $\begin{array}{c}\mathrm{I}_{\mathrm{A}} \\
\text { (mg KOH/g óleo) }\end{array}$ & $\begin{array}{c}\mathrm{I}_{\mathrm{s}} \\
\text { (mg KOH} / \mathrm{g} \text { óleo) }\end{array}$ & $\begin{array}{c}\mathbf{G}_{\mathrm{s}} \\
(\%)\end{array}$ & Fonte \\
\hline Açaí & 10,2 & 198 & - & Costa [II] \\
\hline Andiroba & 15,0 & 197 & - & Costa [II] \\
\hline Macaúba (polpa) & 2,60 & 149,5 & - & Pachêco [I3] \\
\hline Macaúba (Castanha) & 17,70 & 202,4 & 71,55 & Rocha [15] \\
\hline Maracujá & 1,0 & 198,0 & - & Costa [II] \\
\hline Pequi & 0,03 & 191,9 & 70,69 & Silva et al. [16] \\
\hline Pinhão manso & 7,67 & 182,57 & 72,75 & - \\
\hline
\end{tabular}

Índice de acidez $\left(\mathrm{I}_{\mathrm{a}}\right)$, índice de saponificação $\left(\mathrm{I}_{\mathrm{s}}\right)$ e do grau de saponificação $\left(\mathrm{G}_{\mathrm{s}}\right)$. 
Nota-se na figura $2 b$ a presença de uma fase mineral em formato acicular na superfície da apatita. Duas análises de EDS são apresentadas. A Figura $2 c$ refere-se à composição do mineral acicular, onde foram encontrados elementos do grupo da apatita e também prata. A Figura $2 \mathrm{~d}$ apresenta elementos próprios de minerais da família da apatita indicando a presença de cloroapatita e fluorapatita.

As Figuras 3a e $3 \mathrm{~b}$ apresentam incrustações na superfície da calcita (ponto I) indicando a presença de óxidos de ferro (vide figura 3d), elemento este que não foi encontrado na fluorescência de raios-X. Já a análise do ponto 2 (Figura 3c) indica a presença de elementos presentes na calcita.

As Figuras $4 \mathrm{a}$ e $4 \mathrm{~b}$ apresentam pequenas incrustações na superfície das amostras de quartzo. A análise do ponto I (Figura 4c) revelou a presença de óxidos de ferro, coerente com os resultados obtidos por fluorescência de raios-X. Para o ponto 2 (Figura 4d) foram identificados apenas elementos presentes na composição do quartzo. As imagens adquiridas por MEV indicaram que os minerais estavam quase totalmente liberados, com pequenas incrustações em sua superfície. Em nenhuma imagem adquirida foi possível

Tabela 3. Análise das amostras minerais por fluorescência de raios- $X$

\begin{tabular}{crccccc}
\hline $\begin{array}{c}\text { Óxidos } \\
(\%)\end{array}$ & $\mathbf{P}_{2} \mathbf{O}_{5}$ & $\mathbf{K}_{2} \mathbf{O}$ & $\mathbf{C a O}$ & $\mathbf{F e}_{2} \mathbf{O}_{3}$ & $\mathbf{S i O}_{2}$ & Outros \\
\hline Apatita & 38,49 & 4,20 & 54,02 & $0,1 \mathrm{I}$ & $\mathrm{I}, 0$ & $\mathrm{I}, 72$ \\
Calcita & 0,15 & 6,15 & 92,58 & - & - & $\mathrm{I}, 12$ \\
Quartzo & 0,04 & 4,31 & 0,12 & 0,16 & 94,68 & 0,95 \\
\hline
\end{tabular}

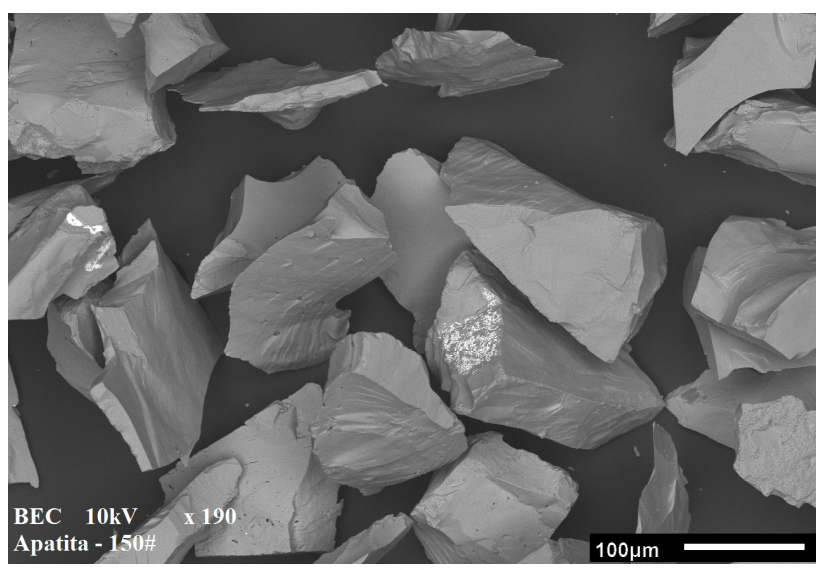

(a)

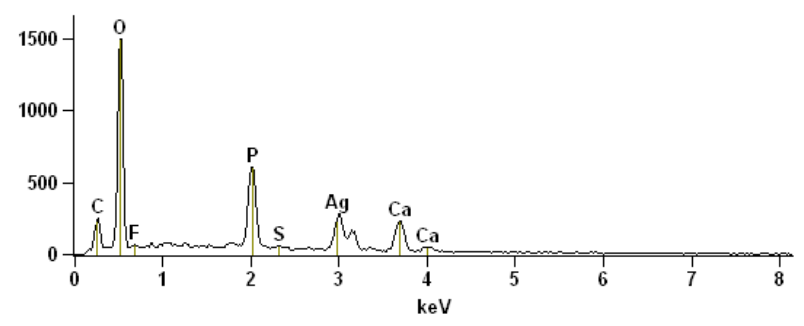

(c) encontrar partículas liberadas de outros minerais presentes nas amostras.

A Figura 5 apresenta os resultados da difração por raios-X das amostras minerais. Como o objetivo era apenas confirmar a fase cristalina das amostras, uma simples busca nos picos de Bragg permitiu confirmar cada um dos minerais. Contudo, passos de refinamento dos resultados foram executados a fim de se ter uma prova irrefutável da composição dos minerais. As amostras de calcita e de quartzo apresentaram orientação preferencial, mas isso não impediu a determinação com precisão da estrutura dos mesmos. A orientação preferencial pode ser consequência do preparo da amostra. Os resultados obtidos não mostraram a presença de outras fases minerais presentes nas amostras.

A Figura 6 apresenta os resultados médios da medição do potencial zeta das amostras minerais. Na faixa de $\mathrm{pH}$ analisada $(3,5$ a 12,5) não foi possível observar o ponto isoelétrico dos minerais. Para a faixa de $\mathrm{pH}$ utilizado nos testes de microflotação $(8$ a 10$)$ a carga superficial dos minerais era negativa, indicando assim a necessidade do emprego de um coletor com carga positiva. Segundo Oliveira [3] para $\mathrm{pHs}$ alcalinos a apatita tem carga negativa e os resultados obtidos pelo autor comprovaram que os coletores aniônicos adsorveram por quimissorção na superfície do mineral. O mesmo mecanismo de adsorção foi notado na calcita quando a superfície da mesma estava carregada negativamente. Durante a realização dos testes não foi observada solubilização de nenhum dos minerais testados.

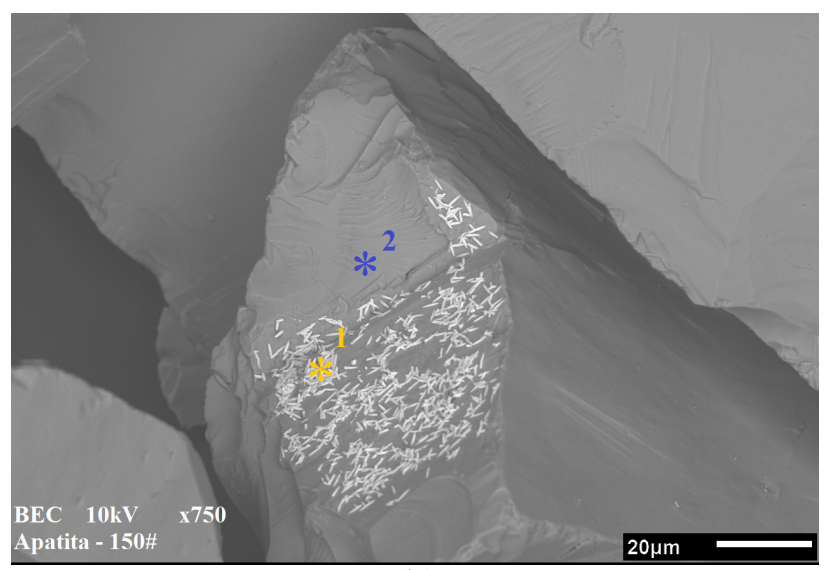

(b)

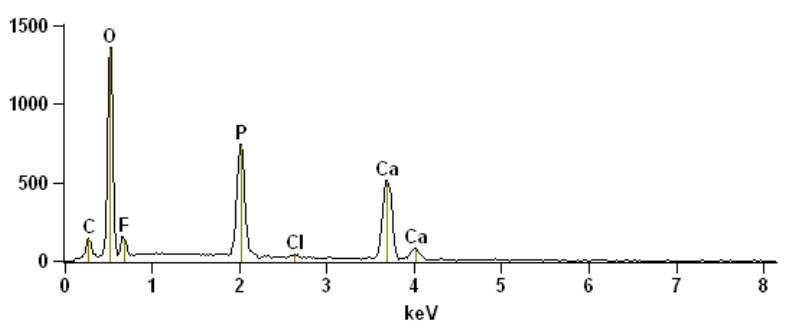

(d)

Figura 2. Imagens obtidas por MEV para amostras de apatita (a) xI90 e (b) x750. Análises por EDS dos pontos I (c) e 2 (d). 


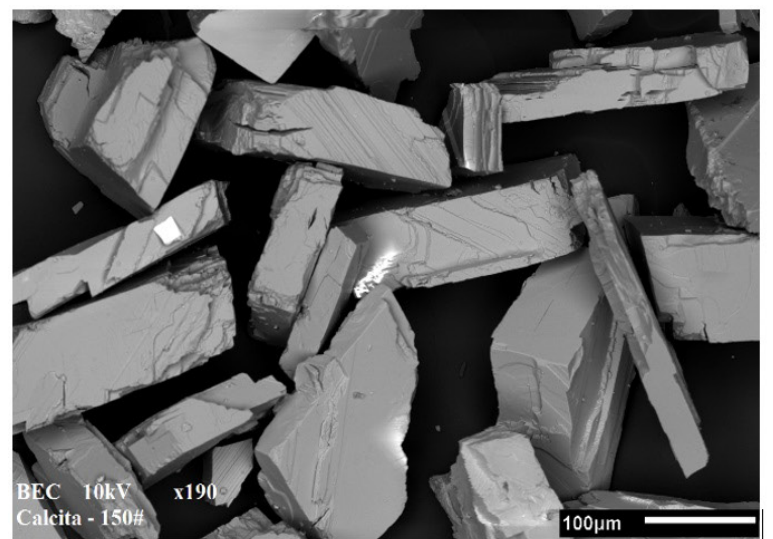

(a)

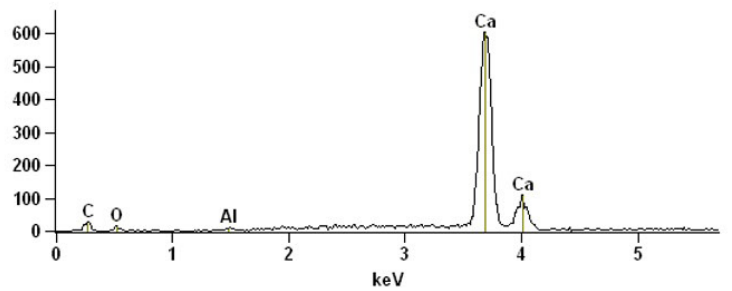

(c)

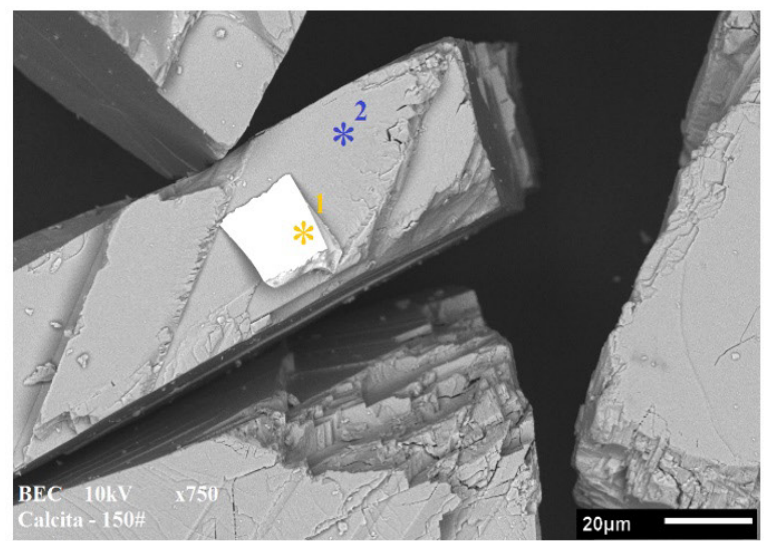

(b)

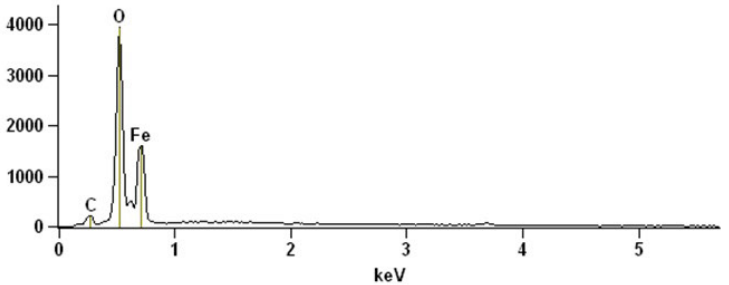

(d)

Figura 3. Imagens obtidas por MEV para amostras de calcita (a) xI90 e (b) x750. Análises por EDS dos pontos I (c) e 2 (d).

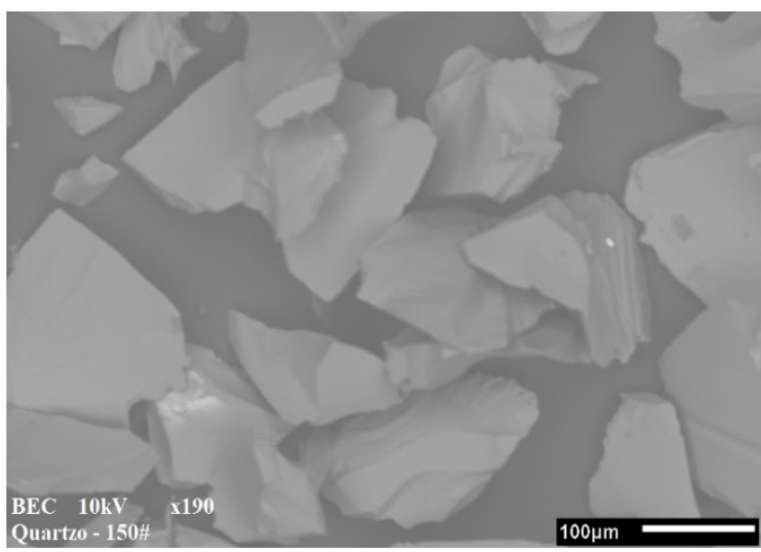

(a)

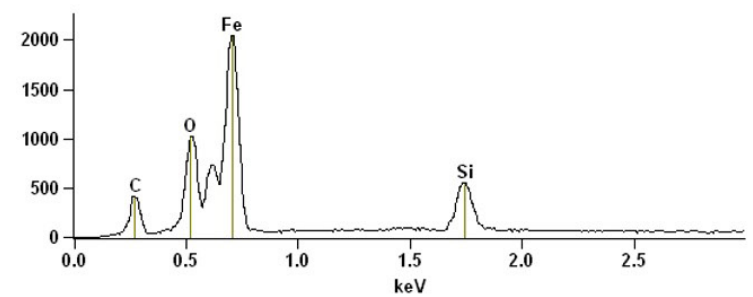

(c)

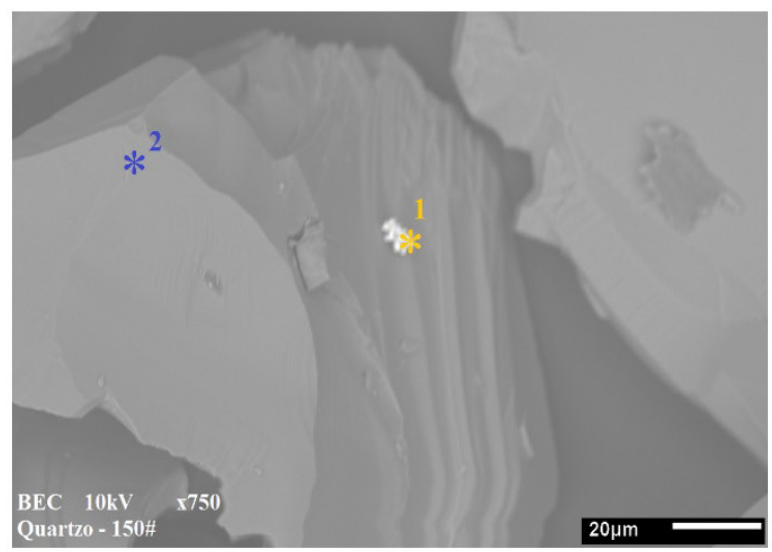

(b)

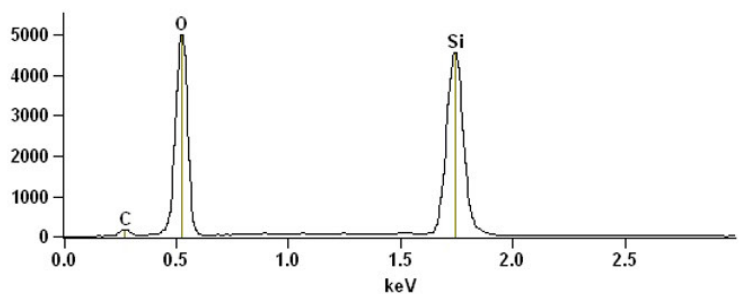

(d)

Figura 4. Imagens obtidas por MEV para amostras de quartzo (a) xI90 e (b) x750. Análises por EDS dos pontos I (c) e 2 (d).

A Figura 7 apresenta os resultados dos testes de microflotação para a apatita. Para os três coletores testados (Flotigam 5806 e óleo de pinhão manso saponificado a quente e a frio) foi possível obter recuperações acima de $90 \%$ para dosagens acima de 7,5 mg/L. Os resultados obtidos estão de acordo com os trabalhos de Silva et al. [16] e de Silva et al. [17] que obtiveram recuperações de apatita semelhantes em testes de microflotação com óleo da castanha da macaúba 


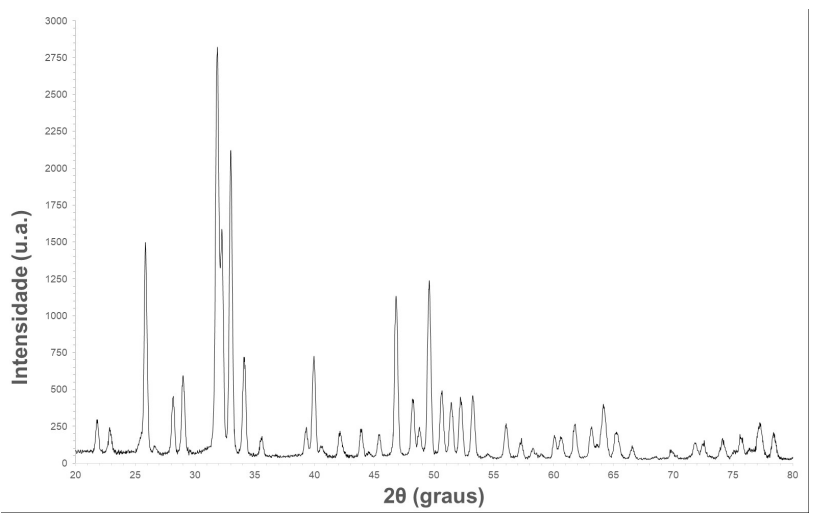

(a)

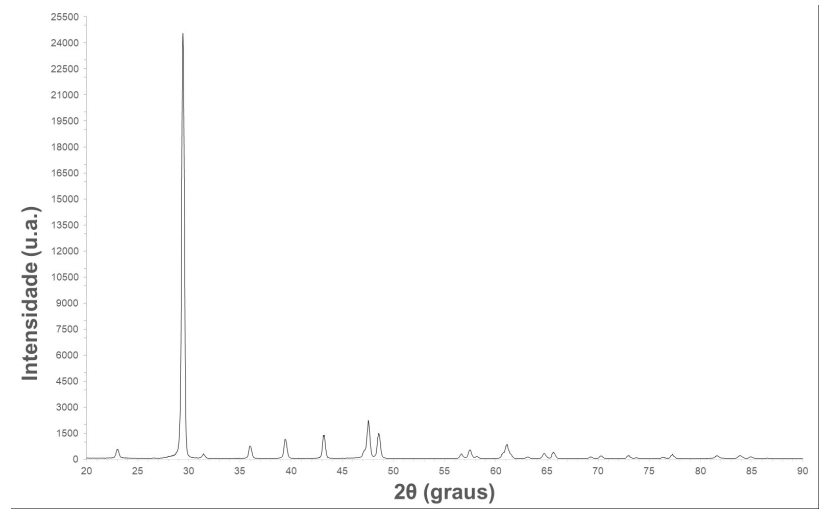

(b)

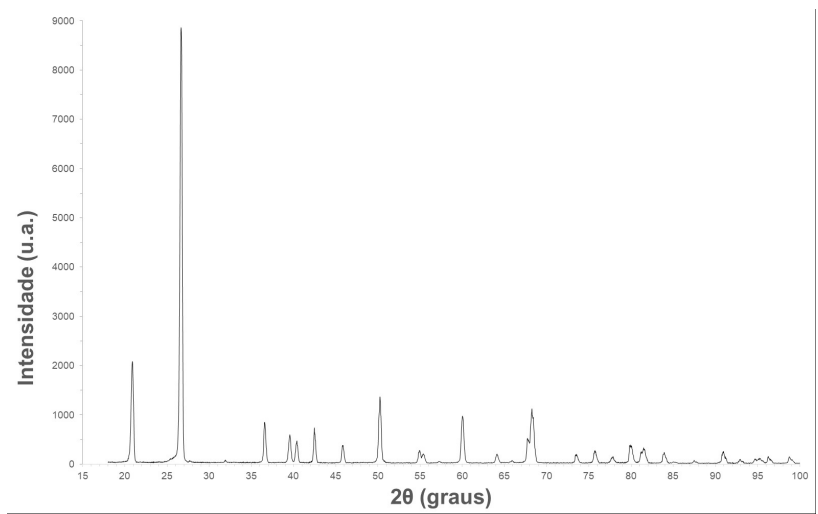

(c)

Figura 5. Resultados da difração de raios-X para as amostras de (a) apatita, (b) calcita e (c) quartzo.

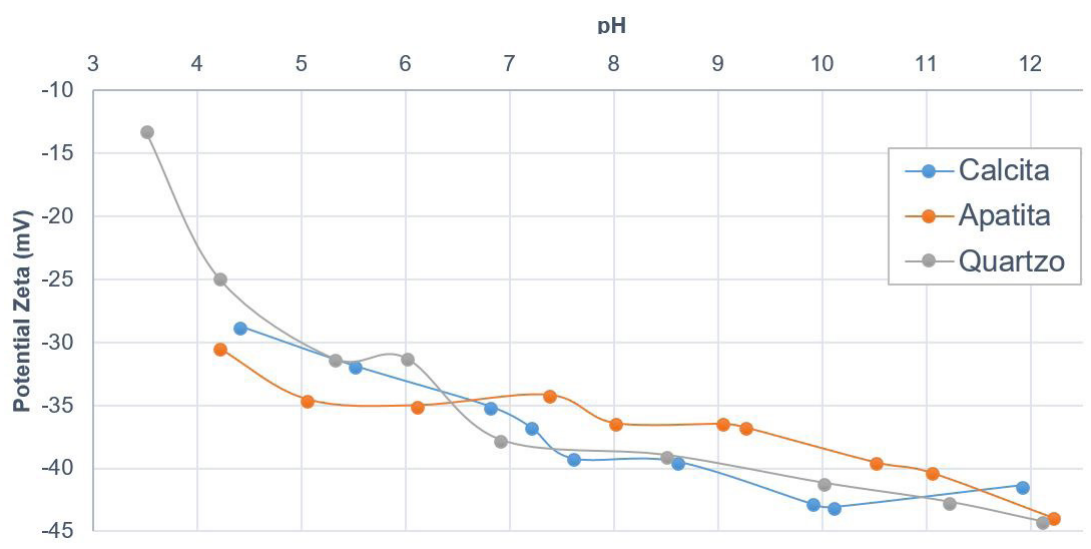

Figura 6. Potencial zeta para as amostras de apatita, calcita e quartzo.

e óleo de pequi. Para todas as dosagens e pHs testados o óleo de pinhão manso saponificado a frio obteve resultados de recuperação superior (ou muito próxima) quando comparado ao outro método de saponificação (a quente). Para os pHs 8 e 9 o Flotigam 5806 obteve recuperação superior ao óleo de pinhão manso saponificado a frio apenas na dosagem de $1,0 \mathrm{mg} / \mathrm{L}$.

A Figura 8 apresenta os resultados dos testes de microflotação para a calcita. É possível notar que óleo de pinhão manso saponificado a quente obteve recuperação inferior a $60 \%$ nos pHs 8 e 9 para todas as dosagens testadas, o que só foi observado para o outro método de saponificação (a frio) e para o Flotigam 5806 na dosagem de I, $0 \mathrm{mg} / \mathrm{L}$. Em todos os pHs e dosagens testados a óleo de pinhão manso saponificado a quente obteve recuperações menores que os outros dois óleos, sendo que em pHs $8 \mathrm{e}$ 9 para dosagens acima de $5,0 \mathrm{mg} / \mathrm{L}$ o aumento da dosagem do coletor gerou uma redução na recuperação da calcita.

A Figura 9 apresenta os resultados para microflotação de quartzo. Nota-se que o óleo de pinhão manso, independentemente do método de saponificação, obteve recuperações de quartzo consideravelmente menores que 


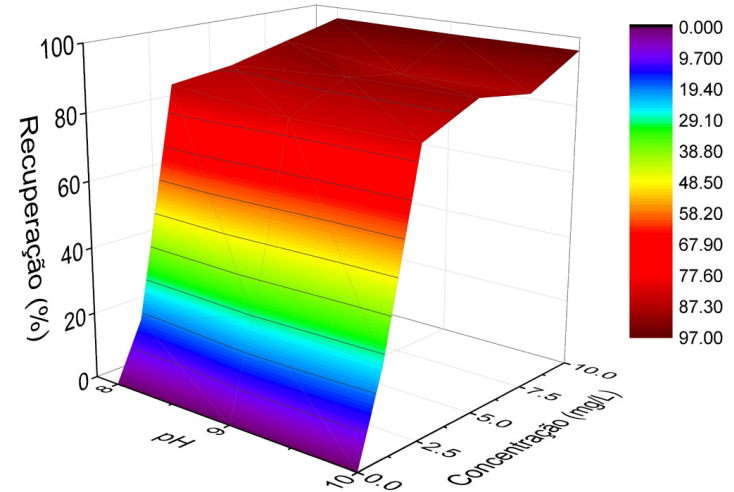

(a)

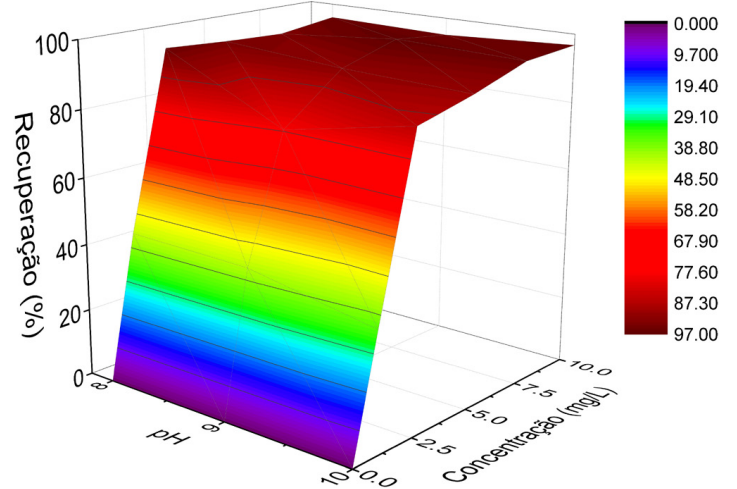

(b)

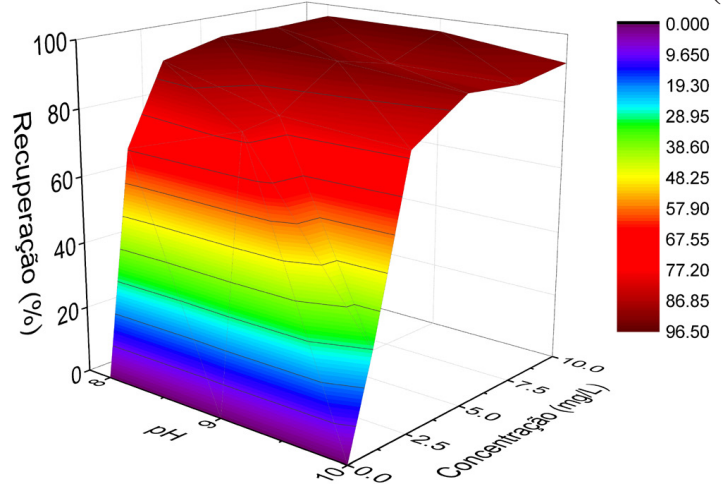

(c)

Figura 7. Recuperação de apatita para os coletores (a) óleo de pinhão manso saponificado a quente, (b) a frio e (c) Flotigam 5806.

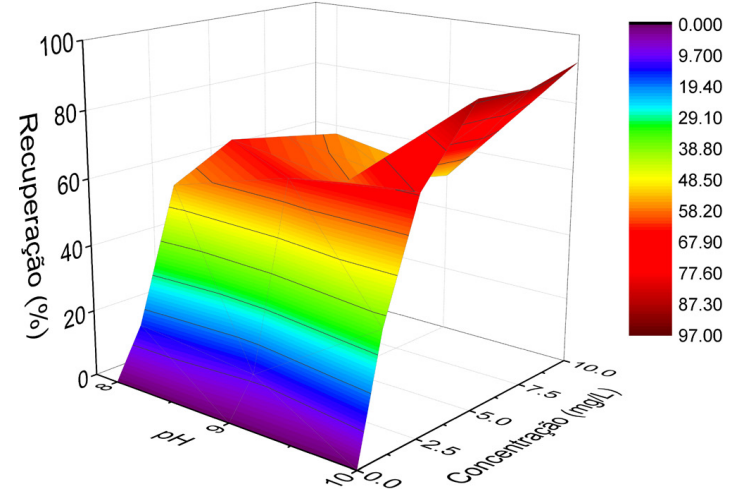

(a)

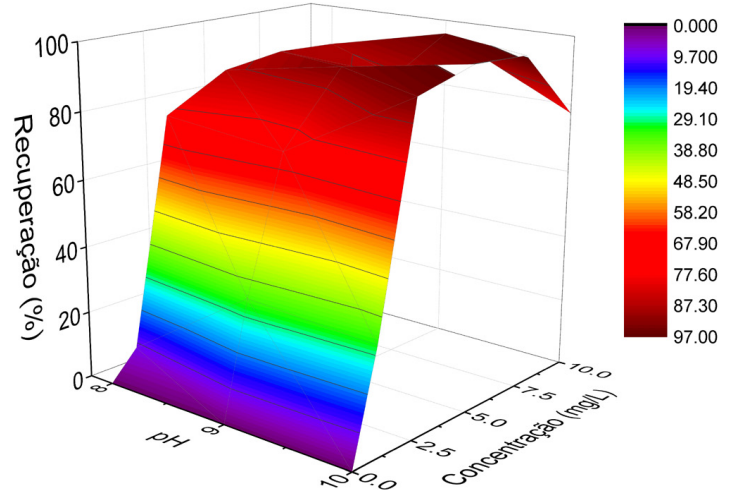

(b)

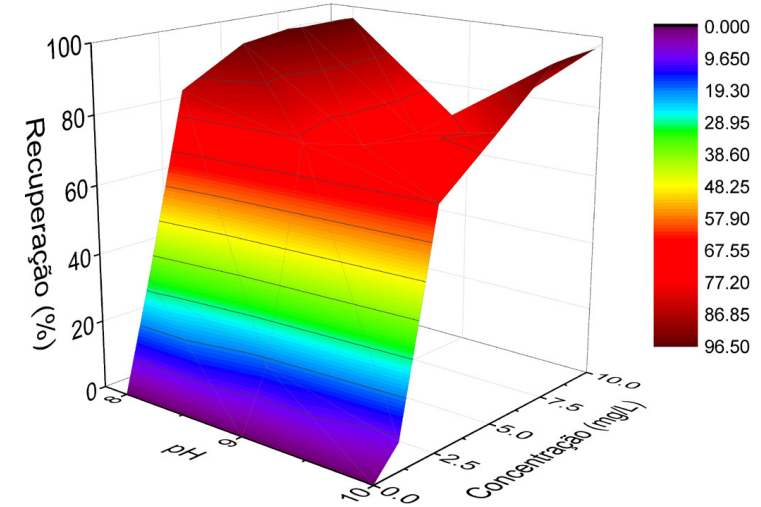

(c)

Figura 8. Recuperação de calcita para os coletores (a) óleo de pinhão manso saponificado a quente, (b) a frio e (c) Flotigam 5806. 


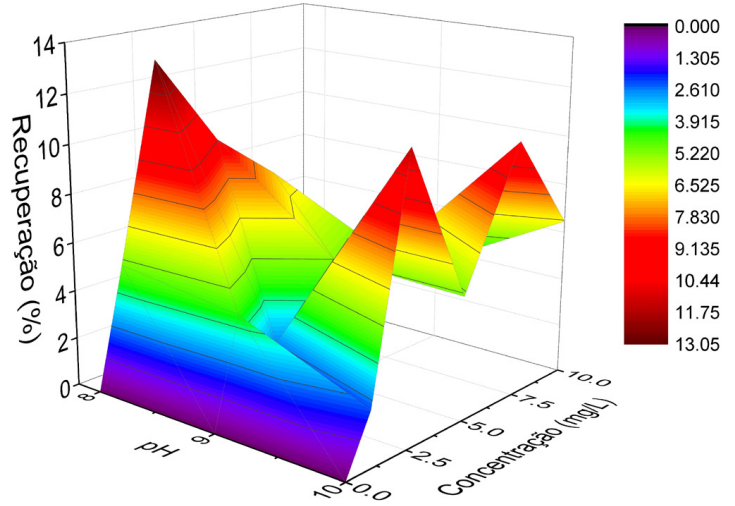

(a)

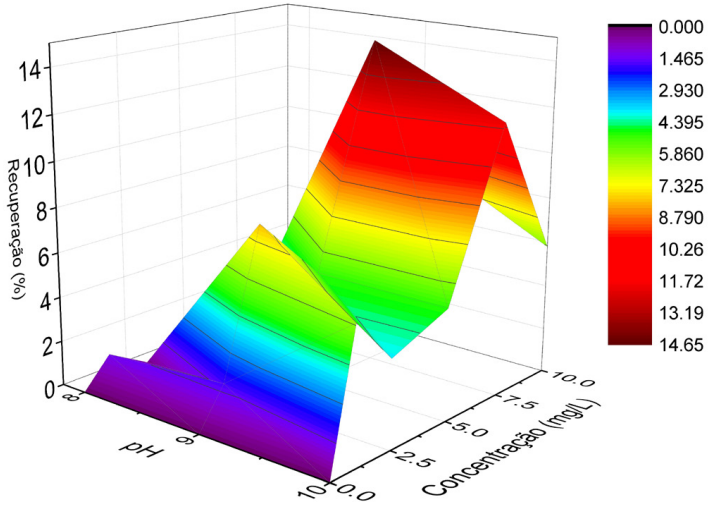

(b)

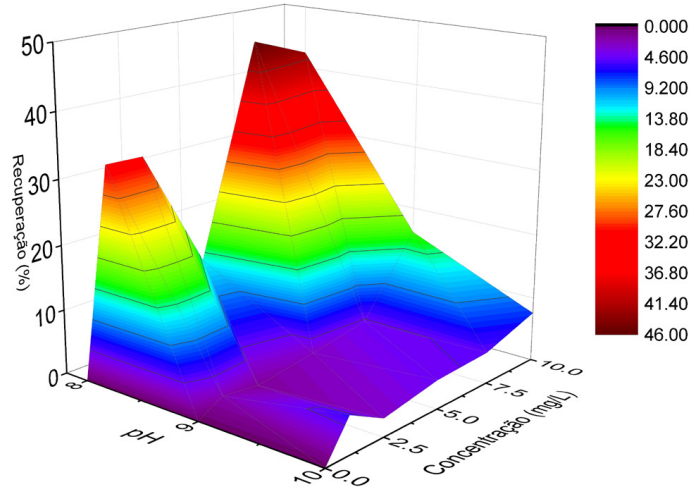

(c)

Figura 9. Recuperação de quartzo para os coletores (a) óleo de pinhão manso saponificado a quente, (b) a frio e (c) Flotigam 5806.

o Flotigam 5806 (menores que 15\%). Destaque pode ser dado ao óleo saponificado a frio no $\mathrm{pH} 8$, com recuperaçóes inferiores a $4 \%$.

\section{CONCLUSÕES}

Os testes de microflotação das amostras minerais, utilizando o óleo de pinhão manso saponificado, indicaram seletividade aos minerais apatita, calcita e quartzo. Quando comparados os resultados da flotação de apatita e de calcita a similaridade das propriedades superficiais dos dois minerais é evidente, com recuperações semelhantes para os coletores testados. Contudo, o óleo de pinhão manso saponificado a quente obteve recuperação de calcita de aproximadamente $50 \%$ e de apatita de $96 \%$ para a dosagem de $10 \mathrm{mg} / \mathrm{L} \mathrm{e} \mathrm{pH}$ 9. Já para o quartzo a recuperação foi de $3,5 \%$ nas mesmas condições operacionais. O óleo de pinhão manso, indiferente ao método de saponificação adotado, se mostrou o coletor mais seletivo ao quartzo, com recuperações desse mineral inferiores às obtidas pelo Flotigam $5806 \mathrm{em}$ todos os pHs e dosagens testados.
Tais dados indicam que o óleo de pinhão manso, quando saponificado a quente, tem potencial para ser utilizado na flotação seletiva de apatita e calcita, bem como de ganga quartzosa, apresentando-se como uma alternativa técnica e economicamente viável aos coletores industriais atualmente utilizados. A utilização desse coletor alternativo, em escala industrial, pode se mostrar uma importante inovação para o setor mineral devido ao baixo preço de mercado do mesmo.

\section{Agradecimentos}

Os autores agradecem o apoio financeiro das agências brasileiras CNPq, CAPES, FAPEG e FUNAPE. Além disso, agradecemos à Embrapa Agroenergia e à Clariant pela doação de amostras, à Copebrás, UFOP, UNIFESSPA e ao Laboratório Multiusuário de Microscopia de Alta Resolução (LabMic/UFG) pelas análises realizadas e à Universidade Federal de Goiás.

\section{REFERÊNCIAS}

I Ribeiro CC. Geologia, geometalurgia, controles e gênese dos depósitos de fósforo, terras raras e titânio do complexo carbonatítico Catalão I, GO [tese]. Brasília: Universidade de Brasília; 2008. 
2 Santana RC. Efeito da altura da coluna na flotação de minério fosfático em diferentes granulometrias [tese]. Uberlândia: Universidade Federal de Uberlândia; $201 \mathrm{I}$.

3 Oliveira MS. Minério fosfático sílico-carbonatado: estudo fundamental [tese]. Belo Horizonte: Universidade Federal de Minas Gerais; 2007.

4 Pugh R, Stenius P. Solution chemistry studies and flotation behaviour of apatite, calcite and fluorite minerals with sodium oleate collector. International Journal of Mineral Processing. 1985; 15:193-218.

5 Monteiro MF. Avaliação do ciclo de vida do fertilizante superfosfato simples [dissertação]. Salvador: Universidade Federal da Bahia; 2008.

6 Abouzeid AZM. Physical and termal treatment of phosphate ores - an overview. International Journal of Mineral Processing. 2008;85:59-84.

7 Loureiro FEVL, Monte MBM, Nascimento M. Rochas e minerais industriais. 2. ed. Rio de Janeiro: Ministério da Ciência e Tecnologia; 2008. p. 14I-180.

8 Purcino AAC, Drummond OA. Pinhão-manso. Belo Horizonte: EPAMIG; 1986.

9 Rosado TB, Laviola BG, Faria DA, Pappas MR, Bhering LL, Quirino B, et al. Molecular markers reveal limited genetic diversity in a large germplasm collection of the biofuel crop Jatropha curcas $\mathrm{L}$. in Brazil. Crop Science. 2010;50:2372-2382. http://dx.doi.org/10.2135/ cropsci2010.02.01 I2.

10 Oliveira JA. Grau de saponificação de óleos vegetais na flotação seletiva de apatita de minério carbonatítico [dissertação]. Ouro Preto: Universidade Federal de Ouro Preto; 2005.

I I Costa DS. Uso de óleos vegetais amazônicos na flotação de minérios fosfáticos [tese]. Belo Horizonte: Escola de Engenharia, Universidade Federal; 2012.

12 Silva TC. Utilização do óleo de pequi como coletor na microflotação de apatita [dissertação]. Catalão: Universidade Federal de Goiás; 2014.

13 Pachêco CAT. Análise técnica e econômica do uso do óleo da polpa de macaúba (Acrocomia Aculeata) como coletor na flotação [dissertação]. Catalão: Universidade Federal de Goiás; 2016.

14 Guimarães P Jr. Silva AC, Silva EMS. Modelling the hydraulic entrainment phenomenon in microflotation. In: Proceedings of the $2^{\text {nd }}$ International Symposium on Sustainable Mineral Processing; 2015 Oct 4-9; Antalya. Turquia: Flogen. 2015. p. 186-192.

15 Rocha TWP. Utilização do óleo da castanha de macaúba como coletor na microflotação da apatita. [dissertação]. Catalão: Universidade Federal de Goiás; 2014.

16 Silva AC, Silva EMS, Rocha TWP. Microflotação de apatita utilizando óleo da castanha de macaúba (Acrocomia Aculeata) como coletor. Revista Tecnologia em Metalurgia, Materiais e Mineração. 2015; 12(2):146-152.

17 Silva TC, Silva AC, Silva EMS. Apatite froth flotation using pequi's yellow pulp oil as collector. In: Proceedings of the World Congress on Mechanical Chemical and Material Engineering; 2015 July 20-2I; Barcelona, Espanha. Orléans: Avestia Publishing; 2015. p. 343-353.

Recebido em: 19 Maio. 2017

Aceito em: 22 Set. 2017 